\title{
ATIVIDADE DA PEROXIDASE DURANTE O PERÍODO HIBERNAL DE PLANTAS DE PESSEGUEIRO (Prunus persica (L.) Batsch.) cv. JUBILEU COM E SEM SINTOMAS DA MORTE PRECOCE ${ }^{1}$
}

\author{
ANDERSON CARLOS MARAFON², FLÁVIO GILBERTO HERTER ${ }^{3}$, \\ MARCOS ANTONIO BACARIN ${ }^{4}$, FERNANDO JOSÉ HAWERROTH ${ }^{5}$
}

RESUMO- A morte precoce do pessegueiro (Prunus persica (L.) Batsch) é uma síndrome caracterizada por um colapso da planta durante a floração ou no início da brotação, após drástica redução da temperatura. O objetivo do presente trabalho foi determinar a atividade da peroxidase (UE $\min ^{-1} \mathrm{~g}^{-1} \mathrm{MF}$ ) durante o período hibernal, em gemas e ramos de plantas de pessegueiro cv. Jubileu, com e sem sintomas de morte precoce. Foram conduzidos dois experimentos separadamente, um para cada tipo de tecido, em dois pomares próximos, ambos com quatro anos de implantação, situados na região colonial de Pelotas - RS, nas localidades de Santa Helena e Cascata. As amostras foram constituídas por dois tipos de tecidos (gemas e ramos) e foram coletadas em quatro datas (11-06, 11-07, 29-07 e 05-08) durante o inverno de 2003. As determinações da atividade da peroxidase nos tecidos foram realizadas no Laboratório de Fisiologia Vegetal da Embrapa Clima Temperado. As plantas com sintomas de morte precoce apresentaram, durante a dormência, maior atividade da peroxidase nos dois tipos de tecidos, quando comparadas com as plantas sem sintomas da síndrome. Provavelmente, o desencadeamento da síndrome provoca alterações na dormência das plantas afetadas, que resultam na antecipação da retomada do crescimento das gemas e na exposição dos tecidos recém-formados aos danos causados pelas baixas temperaturas. Os níveis populacionais do nematoide-anelado (Mesocriconema xenoplax) e dos nematoides do gênero Helicotylenchus sp. foram superiores nas amostras de solo coletadas na rizosfera das plantas com sintomas de morte precoce do que os verificados nas amostras coletadas das plantas sem sintomas da síndrome, resultando também na maior atividade da peroxidase em ambos os tecidos (gemas e ramos), durante o período hibernal das plantas afetadas.

Termos de indexação: Prunus persica, declínio, estresse oxidativo, dormência, nematoides.

\section{PEROXIDASE ACTIVITY DURING THE REST PERIOD OF PEACH TREES (Prunus persica (L.) Batsch) cV. JUBILEU IN PLANTS WITH AND WITHOUT SYMPTOMS OF PEACH-TREE-SHORT-LIFE (PTSL)}

\begin{abstract}
Peach Tree Short Life (PTSL) is a syndrome characterized by a collapse of the peach trees (Prunus persica (L.) Batsch) during the flowering, or in the beginning of the bud break period, after a drastic reduction of the temperature. The aim of the present work was to determine the peroxidase activity (UE min $^{-1} \mathrm{~g}^{-1} \mathrm{MF}$ ) during the dormancy period in buds and twigs tissues of peach trees cv. Jubileu with and without PTSL symptoms. Two experiments were conducted separately, one for each appraised tissue, in two peach orchards with four years of implantation, both located in the colonial region of Pelotas, RS, in the Santa Helena and Cascata districts. The tissues consisted in buds and twigs collected in four dates during the dormancy period (June $11^{\text {th }}$, July $11^{\text {th }}$ July $29^{\text {th }}$, and August $05^{\text {th }}$ ) in 2003 . The peroxidase activity determinations were carried out at the Vegetal Physiology Laboratory of Embrapa Clima Temperado. The plants with symptoms of PTSL showed higher peroxidase activity than the healthy plants along the dormancy period in both tissues analyzed. The syndrome triggering could lead to the dormancy interruption and the premature exposition of the new tissues to the injuries caused by the low temperatures during the winter. Moreover, the population levels of ring nematode (Mesocriconema xenoplax) and of the Helicotylenchus sp. found in the soil of plants with symptoms of PTSL were higher than plants without symptoms, resulting also in the higher peroxidase activity in both tissues (twigs and buds) during the rest period of the attached plants.
\end{abstract}

Index terms: Prunus persica, decline, oxidative stress, dormancy, nematodes.

\footnotetext{
1'(Trabalho 281-08). Recebido em: 13-11-2008. Aceito para publicação em: 14-07-2009.

¿2Eng. Agr. Dr., Pesq. colaborador, Projeto Xisto Agrícola, Embrapa Clima Temperado, Rod BR 392, km 78, C.P. 403, 96001-970, Pelotas-RS. e-mail: anderson.marafon@gmail.com

${ }^{3}$ Engo. Agro. Dr., Docente do Curso de Pós-graduação em Fruticultura da Ufpel, FAEM, Depto. de Fitotecnia, C. P. 354, 96010-900, Pelotas-RS. e-mail: flavioherter@gmail.com

${ }^{4}$ Eng. Agr. Dr., Docente do Curso de Pós-graduação em Fisiologia Vegetal da Ufpel, Inst. de Biologia, Depto. de Botânica, Caixa Postal 354, 96010-900, Pelotas-RS. e-mail: bacarin@ufpel.edu.br

${ }^{5}$ Eng. Agr. MSc., Doutorando do Curso de Pós-graduação em Fruticultura, Universidade Federal de Pelotas, Faculdade de Agronomia Eliseu Maciel, Departamento de Fitotecnia, Caixa Postal 354, 96001-015, Pelotas-R.S. e-mail: hawerrothfj@hotmail.com
} 


\section{INTRODUÇÃO}

A morte precoce do pessegueiro (Prunus persica (L.) Batsch) constitui-se numa das principais causas de perdas de plantas na cultura do pessegueiro no Rio Grande do Sul. A síndrome é caracterizada por um colapso da planta durante a floração, ou no início da brotação, após drástica redução da temperatura. Ao final da dormência, a paralisação do crescimento da planta é evidenciada pelos baixos índices de brotação e floração, pelo escurecimento dos tecidos internos do lenho e pela exalação de um forte odor alcoólico, característico de fermentação, durante a poda (Fortes \& Osório, 2003).

A morte precoce é consequência de muitos fatores desencadeantes, que predispõem ou enfraquecem a planta, associados às oscilações bruscas de temperatura no período de quebra da dormência. Dentre os fatores predisponentes, destacam-se: deficiência ou toxidez por nutrientes; solos ácidos ( $\mathrm{pH}<6,0)$, encharcados ou com déficit hídrico; ferimentos nas raízes; podas prematuras, e ocorrência do nematoide-anelado (Mesocriconema xenoplax) em porta-enxertos suscetíveis a este parasita (Medeiros \& Raseira, 1998).

As peroxidases (E.C. 1.11.1.7) são enzimas oxidativas envolvidas em vários processos fisiológicos vegetais, como nas reações de oxidação do ácido indol-3-acético, lignificação da parede celular, oxidação de compostos fenólicos, ligações de polissacarídeos, cicatrização de ferimentos, resposta a injúrias mecânicas, biossíntese de etileno, desenvolvimento celular, integridade das membranas celulares e na defesa contra patógenos (Gaspar et al., 1982).

A atividade da peroxidase é frequentemente aumentada em resposta a estresses, pois uma das suas principais funções é a proteção celular contra reações oxidativas em diversos tecidos vegetais (Siegel, 1993).

O objetivo do presente trabalho foi comparar a atividade da enzima peroxidase em tecidos de gemas e ramos de plantas de pessegueiro cv. Jubileu com e sem sintomas de morte precoce durante o período hibernal.

\section{MATERIAIS E MÉTODOS}

Esta pesquisa foi conduzida em dois pomares de pessegueiro cv. Jubileu, enxertados sobre portaenxertos oriundos de caroços da indústria de conserva, ambos com quatro anos de implantação, situados na região colonial de Pelotas - RS, distantes $4 \mathrm{~km}$ entre si, um deles com sintomas de morte precoce e o outro sem sintomas. Segundo a classificação climática de Köeppen, Pelotas tem o clima do tipo subtropical úmido (Cfa), com precipitação uniforme e bem distribuída ao longo do ano e temperaturas no mês mais frio entre -3 e $18^{\circ} \mathrm{C}$.

Foram conduzidos dois experimentos, separadamente, um para cada tipo de tecido coletado (gemas e ramos), segundo um delineamento experimental inteiramente casualizado com três repetições, num arranjo fatorial $2 \times 4$, dois níveis do fator síndrome (plantas com e sem sintomas) e quatro níveis do fator época (11-06; 11-07; 29-07 e 05-08). Os dados obtidos foram submetidos à análise de variância e comparação de médias, pelo teste de Tukey a 5\%.

As amostras para a determinação da atividade da peroxidase foram constituídas por gemas e ramos, sendo coletadas em quatro épocas de coleta, durante o inverno de 2003. Após serem coletados, os tecidos foram congeladas em nitrogênio líquido $\left(\mathrm{N}_{2}\right)$ e ficaram armazenados em ultrafreezer $\left(-70^{\circ} \mathrm{C}\right)$ até o momento das análises, que foram efetuadas no Laboratório de Fisiologia Vegetal da Embrapa Clima Temperado, seguindo a metodologia descrita por Campos \& Silveira (2003). A atividade da peroxidase foi expressa em UE $\mathrm{min}^{-1} \mathrm{~g}^{-1} \mathrm{MF}$, e a unidade da enzima (UE), por grama de massa fresca (MF), definida como a quantidade de extrato enzimático que resulta no aumento de 0,001 na absorbância a $450 \mathrm{~nm}$.

Foram efetuadas análises nematológicas de amostras de solo coletadas da rizosfera das plantas, com e sem sintomas de morte precoce. Adeterminação dos níveis populacionais dos nematoides presentes nas amostras do solo foi efetuada pelo Laboratório de Nematologia da Embrapa Clima Temperado, e os resultados destas análises foram comparados pelo teste $\mathrm{F}$.

\section{RESULTADOS E DISCUSSÃO}

\section{Atividade da Peroxidase}

Foi constatada diferença significativa $(\mathrm{P}<0,05)$ para a atividade da enzima (UE $\mathrm{min}^{-1} \mathrm{~g}^{-1}$ $\mathrm{MF}$ ) entre as plantas com e sem sintomas de morte precoce. Em todas as épocas de coleta, a atividade da enzima foi significativamente superior nas plantas com sintomas de morte precoce, tanto nas gemas quanto nos ramos (Figura 1).

A maior atividade da peroxidase nos tecidos, durante o período de repouso das plantas com sintomas de morte precoce, provavelmente, ocorre em resposta a uma situação de estresse fisiológico, decorrente do desencadeamento da síndrome ainda durante o período vegetativo, interferindo na dormência e aumentando a suscetibilidade dos tecidos ao frio.

Kuroda e Sagisaka (1998) demonstraram que tanto as catalases, quanto as peroxidases aumentam abruptamente em ramos de macieira durante os primeiros estágios de aclimatação ao frio. Enquanto a catalase está envolvida na remoção de $\mathrm{H}_{2} \mathrm{O}_{2}$ (peróxido de hidrogênio), produzido durante as reações de síntese de proteínas, organelas e ATP, a peroxidase 
atua tanto no sentido da síntese quanto da degradação do $\mathrm{H}_{2} \mathrm{O}_{2}$, estando relacionada aos processos de lignificação e destruição da auxina natural, uma função essencial para reduzir a atividade celular e, consequentemente, o crescimento da planta.

A produção de formas de oxigênio reativo seria aumentada em situações de estresse, induzidos por fatores abióticos (baixas temperaturas, déficit hídrico e alta intensidade luminosa) e/ou bióticos (ataque de patógenos). As formas de oxigênio reativo, como os radicais livres superóxido $\left(\mathrm{O}_{2}^{-}\right)$e hidróxido $\left(\mathrm{OH}^{-}\right)$, e $\mathrm{H}_{2} \mathrm{O}_{2}$, são moléculas altamente tóxicas às células, capazes de provocar injúrias oxidativas como: peroxidação de lipídios, desnaturação de proteínas e mutações no DNA (Apel \& Hirt, 2004). $\mathrm{O} \mathrm{H}_{2} \mathrm{O}_{2}$ desempenha duas funções importantes na fisiologia da planta, pois: (1) é tóxico em baixas concentrações (10mM) por inibir a fotossíntese, e (2) é essencial para a biossíntese de lignina (Gaspar et al., 1982).

Foi observada a redução significativa $(\mathrm{P}<0,05)$ e gradativa na atividade da peroxidase nas gemas das plantas sem sintomas de morte precoce durante a dormência. Esta redução também ocorreu nas gemas das plantas com sintomas, porém na fase próxima à brotação. Possivelmente, a redução na atividade da enzima teria ocorrido em função da ativação da enzima catalase, a qual é fundamental na remoção do excesso de $\mathrm{H}_{2} \mathrm{O}_{2}$ das células. De acordo com Faust \& Wang (1993), a redução na atividade da peroxidase está relacionada com a ativação da catalase, no fornecimento de oxigênio aos tecidos, aumento na quantidade de auxinas, especialmente do ácido indolacético e na diminuição da produção de etileno.

Ao contrário do que foi observado nas gemas, houve aumento significativo $(\mathrm{P}<0,05)$ na atividade da peroxidase nos tecidos dos ramos das plantas sem sintomas de morte precoce, nas três primeiras coletas e redução na última coleta, na fase próxima da brotação (Figura 1). De acordo com Boller et al. (1979), o aumento na atividade desta enzima em ramos de pessegueiro estaria relacionado ao processo de conversão do ácido 1-aminociclopropano-1-carboxílico (ACC) em etileno, por meio de reações oxidativas que consomem $\mathrm{H}_{2} \mathrm{O}_{2}$.

Wang et al. (1991) sugeriram que o $\mathrm{H}_{2} \mathrm{O}_{2}$ presente em gemas de macieira seria proveniente de reações catalisadas pelas peroxidases, cujas atividades seriam induzidas pelo frio e/ou pela aplicação de indutores de brotação. A baixa atividade da catalase durante a dormência também contribuiria para o aumento da concentração de $\mathrm{H}_{2} \mathrm{O}_{2}$ nestes tecidos.

$\mathrm{O}$ desencadeamento da síndrome da morte precoce pode ter contribuído para uma antecipação na superação da dormência das plantas com sintomas, aumentando, dessa forma, a suscetibilidade dos tecidos ao frio. A manutenção da alta atividade da peroxidase, nestas plantas, acarretaria no acúmulo de $\mathrm{H}_{2} \mathrm{O}_{2}$ nos tecidos, que provocaria alterações respiratórias transitórias pela inibição de enzimas da via glicolítica e do ciclo dos ácidos tricarboxílicos e o favorecimento da via fermentativa (anaeróbia). Desse modo, haveria uma reorientação do fluxo de carbono para a via das pentoses-fosfato, uma alternativa para regular os níveis celulares de $\mathrm{H}_{2} \mathrm{O}_{2}$, induzindo, assim, a superação da fase de dormência (Kuroda et al., 1990).

Na fase próxima à brotação das gemas, as membranas celulares das plantas de clima temperado mudam sua composição lipídica e tornam-se altamente permeáveis para permitir o transporte de solutos. O processo de desaturação dos lipídios da membrana requer a geração de um grande poder redutor e uma alta atividade de enzimas de degradação do $\mathrm{H}_{2} \mathrm{O}_{2}$, como catalase e peroxidase. Ambas atuam na degradação do $\mathrm{H}_{2} \mathrm{O}_{2}$, sendo que a peroxidase necessita de um doador de hidrogênio e libera, além do oxigênio $\left(\mathrm{O}_{2}\right)$, radicais livres altamente tóxicos às células. Altas concentrações de $\mathrm{H}_{2} \mathrm{O}_{2}$ e de outras formas de oxigênio reativo causariam injúrias às células, como a peroxidação dos lipídios (Faust et al., 1997).

\section{Análises nematológicas do solo}

Dentre os vários fitonematoides detectados na análise das amostras de solo coletadas na rizosfera das plantas com e sem sintomas de morte precoce, o nematoide anelado (Mesocriconema xenoplax) foi o que ocorreu em maior quantidade, em ambos os pomares, seguido pelos nematoides do gênero Helicotylenchus sp.. Os níveis populacionais médios do $M$. xenoplax foram significativamente superiores $(\mathrm{P}<0,05)$ nas amostras de solo das plantas com sintomas de morte precoce (134,29 nematoides 100 / $\mathrm{cm}^{3}$ de solo) do que nas amostras das plantas sem sintomas da síndrome (41,14 nematoides $100 / \mathrm{cm}^{3}$ de solo). Os coeficientes de variação foram de elevada magnitude devido ao fato de que a ocorrência e a frequência de nematoides no solo não ocorrem de forma homogênea (Tabela 1).

Carneiro et al. (1993) também verificaram a existência de correlação entre a presença do nematoide anelado ( $M$. xenoplax) com a ocorrência da síndrome da morte precoce do pessegueiro em pomares da região da Encosta Sudoeste da Serra do RS (região de Pelotas). Dentre as espécies de nematoides detectadas com maior frequência também foram citadas: Meloidogyne incognita, M. Javanica, Helicotylenchus sp. e Xiphinema sp..

O nematoide anelado (M. xenoplax) alimentase nas raízes, em todas as fases de sua vida, induzindo alterações celulares nos locais onde ele ataca. Nos Estados Unidos, o limiar de dano econômico para a cultura do pessegueiro é de cerca de 50 nematoides por $100 \mathrm{~cm}^{3}$ de solo, mas, desde que mantidas as populações abaixo deste nível, o prolongamento da vida e a manutenção da produtividade dos pomares ficariam assegurados (Fortes \& Osório, 2003).

Provavelmente que, durante o período hiber- 
nal, o ataque dos nematoides ao sistema radicular das plantas de pessegueiro com sintomas de morte precoce tenha provocado uma situação de estresse que contribuiu para a formação e o acúmulo de $\mathrm{H}_{2} \mathrm{O}_{2}$ nos tecidos, o que resultou em distúrbios fisiológicos. O aumento de atividade da enzima peroxidase, associado aos ferimentos em vegetais, implica o aumento da síntese de lignina (proteção contra a infecção microbiana), no aumento na concentração de produtos resultantes da oxidação dos compostos fenólicos e na alteração da concentração de auxinas (Marriot et al., 1978).

Nyczepir \& Lewis (1980) constataram redução na concentração de ácido indolacético em raízes de porta-enxertos de Prunus persica cv.
Nemaguard, considerados suscetíveis ao ataque do nematoide anelado ( $M$. Xenoplax). Nos ramos, houve grandes flutuações nos níveis deste regulador de crescimento que, possivelmente, tenham interferido na antecipação da superação da endodormência, predispondo as plantas afetadas às injúrias provocadas pelo frio, com possíveis danos ao câmbio vascular (George \& Carter,1976).

A elevada atividade metabólica no sistema radicular de cultivares de pessegueiros suscetíveis à morte precoce poderia ser explicada pelos distúrbios fisiológicos provocados pelo parasitismo por $M$. Xenoplax, já que o ataque do nematoide provavelmente resulte na translocação das reservas de carboidratos dos ramos para as raízes (Olien et al., 1995).

TABELA 1 - Populações médias de nematoides em pomares de pessegueiro (Prunus persica (L.) Batsch) cv. Jubileu, em plantas com e sem histórico de morte precoce, durante o período de dormência. Pelotas-RS, 2003.

\begin{tabular}{|c|c|c|c|c|}
\hline \multirow{2}{*}{ Nematoide } & $\begin{array}{l}\text { Plantas sem histórico } \\
\text { da morte precoce }\end{array}$ & $\begin{array}{l}\text { Plantas com histórico } \\
\text { da morte precoce }\end{array}$ & \multirow[t]{2}{*}{$\mathrm{F}$} & \multirow{2}{*}{ CV (\%) } \\
\hline & \multicolumn{2}{|c|}{ Número de nematoides $/ 100 \mathrm{~cm}^{3}$ de solo } & & \\
\hline Mesocriconema xenoplax & 41,14 & 134,29 & $5,43^{*}$ & 85,3 \\
\hline Meloidogyne sp. & 11,71 & 5,29 & 1,80ns & 105,4 \\
\hline Helycotylenchus sp. & 32,00 & 4,71 & $19,92 * *$ & 62,3 \\
\hline Pratylenchus sp. & 1,29 & 5,86 & 1,69ns & 184,4 \\
\hline Tylenchus sp. & 8,29 & 2,14 & $4,10 \mathrm{~ns}$ & 108,8 \\
\hline Xiphinema sp. & 0,57 & 7,71 & $1,26 \mathrm{~ns}$ & 287,6 \\
\hline Hoplolaimus sp. & 0,57 & 0,00 & 1,00ns & 374,2 \\
\hline Média Geral & 13,65 & 22,86 & & \\
\hline
\end{tabular}

*, ** significativo pelo teste F, a 5\% e a 1\% de probabilidade de erro, respectivamente; ns - não significativo.
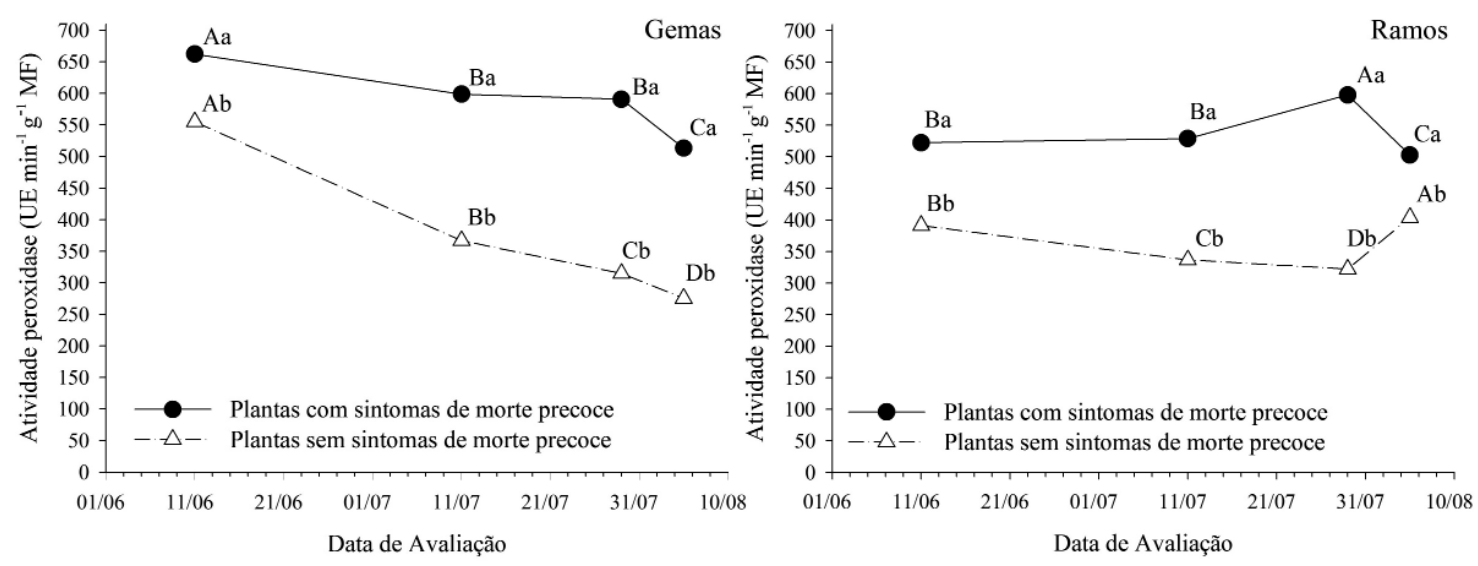

Médias seguidas por letras maiúsculas iguais no sentido horizontal ou por letras minúsculas iguais no sentido vertical não diferem estatisticamente entre sí, pelo teste Tukey $(\mathrm{P}<0,05)$ Coeficiente de variação = 2,09\%.

FIGURA 1 - Atividade da peroxidase (UE $\min ^{-1} \mathrm{~g}^{-1} \mathrm{MF}$ ) durante o período hibernal, em gemas e ramos de plantas de pessegueiro (Prunus persica (L.) Batsch) cv. Jubileu, com e sem sintomas de morte precoce. Pelotas-RS, 2008. 


\section{CONCLUSÕES}

1-Plantas de pessegueiro cv. Jubileu com sintomas de morte precoce apresentam maior atividade da enzima peroxidase nos tecidos das gemas e dos ramos durante o período hibernal em relação às plantas sem sintomas da síndrome.

2-Os níveis populacionais do nematoide anelado ( $M$. xenoplax) e dos nematoides do gênero Helicotylenchus sp. foram superiores nas amostras de solo coletadas na rizosfera das plantas com sintomas de morte precoce do que nas da rizosfera das plantas sem sintomas.

\section{REFERÊNCIAS}

APEL, K.; HIRT, H. Reactive oxygen species: metabolism, oxidative stress, and signal transduction. Annual Review of the Plant Biology, Palo Alto, v. 55, p. 373-399, 2004.

BOLLER, T.; HERNER, R. C.; KENDE, H. An assay for the ethylene precursor 1-aminocyclopropane-1carboxylic acid and studies on its enzymatic formation. Planta, Berkeley, v. 145, p. 293-303, 1979.

CAMPOS, A. D.; SILVEIRA, E. M. L. Metodologia para a determinação da peroxidase e da polifenol oxidase em plantas. Pelotas: Embrapa Clima Temperado, 2003. 3p. (Comunicado Técnico,87).

CARNEIRO, R. M. D. G.; FORTES, J.; ALMEIDA, M. R. A. Associação de Criconemella xenoplax com a morte precoce do pessegueiro no Rio Grande do Sul. Nematologia Brasileira, Piracicaba, v. 17, p. 122-131, 1993.

FAUST, M.; WANG, S. Y. Biochemical events associated with resumption of growth in temperate zone fruit trees Acta Horticulturae, Copenhagen, n. 329, p. 257-264, 1993.

FAUST, M.; EREZ, A.; ROWLAND, J. L.; WANG, S. Y.; NORMAN, H. A. Bud dormancy in perennial fruit trees: Physiological basis for dormancy induction, maintenance and release HortScience, Alexandria, v. 32, p. 623-629, 1997.

FORTES, J. F.; OSÓRIO, V.A. Pêssego: fitossanidade. Brasília: Embrapa Clima Temperado, Informação Tecnológica, 2003. 53p. (Frutas do Brasil, 50).

GASPAR, T. H.; PENEL, C. L.; THORPE, T.; GREPPIN, H. Peroxidases: a survey of their biochemical and physiological roles in higher plants. Genève: Université de Genève, 1982. 544 p.
GEORGE, L. J.; CARTER, J. R. Effect of soil fumigation and pruning date on the indolacetic acid content of peach trees in a short life site. Hortscience, Alexandria, v. 11, n. 6, p. 594-596, 1976.

KURODA, H.; SAGISAKA, S.; CHIBA, K. Frost induces cold acclimatation and peroxide-scavening systems coupled with the pentose phosphate cycle in apple twigs under natural conditions. Journal of Japanese Society for the Horticultural Science, Tokyo, v. 59, n. 2, p. 409-416, 1990.

KURODA, H.; SAGISAKA, S. Participation of hydrogen peroxide in the dysfunction of peroxidescavenging systems in apple flower buds associated with freezing injury. Journal of Japanese Society for the Horticultural Science, Tokyo, v. 67, n. 2, p.161-165, 1998.

MARRIOT, J.; BEEN, B. O.; PERKINS, C. The ethiology of the vascular streaking in cassava roots after harvest: association with water loss from wounds. Plant Physiology, Bethesda, v. 44, n. 1, p. 38-42, 1978.

MEDEIROS, C. A. B.; RASEIRA, M. C. A Cultura do pessegueiro. Pelotas: Embrapa Clima Temperado, 1998, p. 280-296.

NYCZEPIR, A. P.; LEWIS, S. A. The influence of Macrospostania xenoplax Rastri on indole-3-acetic acid (IAA) and abscisic acid (ABA) in peach. The Journal of Nematology, Pennsylvania, v. 12, n. 4, p. 234-236, 1980.

OLIEN, W. C.; GRAHAM, C. J.; HARDIN, M. E.; BRIDGES, W. C. Peach rootstock differences in ring nematode tolerance related to effects on tree dry weight, carbohydrate and prunasin contents. Physiologia Plantarum, Copenhagen, v. 94, n. 1, p. 117-123, 1995.

SIEGEL, B. Z. Plant peroxidases: An organismic perspective - review. Plant Growth Regulation, Nova York, v. 12, n. 3, p. 303-312, 1993.

WANG, S. Y.; JIAO, H. J.; FAUST, M. Changes in the activities of catalase, peroxidase and polifenol oxidase in apple buds during bud break induced by thidiazuron. Journal of the Plant Growth Regulation, Berlin, v. 10, n. 1, p. 33-39, 1991. 